\title{
WETLAND MAPPING WITH MULTITEMPORAL SENTINEL RADAR REMOTE SENSING IN THE SOUTHEAST REGION OF BRAZIL
}

\author{
J. B. G. Salinas ${ }^{1}$, M. K. P. Eggerth ${ }^{2}$, M. E. Miller ${ }^{3}$, R. R. B. Meza ${ }^{1}$, J. T. A. Chacaltana ${ }^{2}$, J. R. Acuña ${ }^{1}$, G. F. Barroso ${ }^{3}$
}

\author{
${ }^{1}$ Facultad de Ciencias Físicas, Universidad Nacional Mayor de San Marcos, Lima, Peru - (jguerreros@unmsm.edu.pe, \\ rolando.badaracco@unmsm.edu.pe,jrojasa@unmsm.edu.pe) \\ ${ }^{2}$ PPGEA, Universidade Federal do Espírito Santo, Vitória, Espírito Santo, Brazil (mirela.plaster@gmail.com, \\ julio.chacaltana@ufes.br) \\ ${ }^{3}$ PPGOAM, Universidade Federal do Espírito Santo, Vitória, Espírito Santo, Brazil (manuel.miller@gmail.com, \\ gilberto.barroso@ufes.br)
}

KEY WORDS: Wetlands, SAR, Multitemporal, Classification, Sentinel-1

\begin{abstract}
A classification method with multi-temporal images of synthetic aperture radar (SAR) combined with Geographic information system, geoinformation data, and field validation, was applied for wetland mapping accuracy and typology. Wetland mapping is vital for management and conservation, particularly under environmental pressures such as wetland drainage and land reclamation. The aim of this study is to develop an accurate mapping of wetlands and open water systems of the Lower Doce River Valley - LDRV (Southeastern Brazil) with Synthetic Aperture Radar (SAR) imagery, using multitemporal classification techniques and ground truth validation. Sentinel-1B SAR imagery from 2016 and 2019 was processed with Google Earth Engine (GEE). Monthly median imagery condition for the rainy season was obtained and K-means unsupervised classification was applied. The study yields 4,157 wetlands, $262.27 \mathrm{~km}^{2}$ with predominant small patches. Fieldwork revealed three main wetlands categories: coastal wetlands, inland wetlands and artificial wetlands. The results have shown an overall accuracy of $81.9 \%$ and a Kappa coefficient of 0.71 . Wetlands, non-wetlands, and open waters classes present accuracy of 50, 80 and 95\%, respectively.
\end{abstract}

\section{INTRODUCTION}

Wetlands are ecosystems of shallow water or saturated soil, with organic matter content of the slow decay of plants, supporting a variety of plants and animals adapted to the saturated conditions and with high primary productivity (Mitsch and Gosselink, 2000). Permanent or temporary inland, coastal and artificial wetlands may comprise several types of hydrological conditions, such as lentic and flowing waters, under different salinity ranges (i.e., freshwater, brackish and marine) with different vegetation features, such as herbaceous, shrub, and forest cover. This complexity has been classified under different wetland typology schemes, such as RAMSAR (1971) and the Brazilian typology (Junk et al., 2014).

As a key component of the landscape, wetlands regulate hydrological cycles in river basins and provide several ecosystems services, such as coastline protection, climate regulation, carbon sink, water cycling and groundwater recharge, pollution abatement, food provision and landscape aesthetics (Barbier et al., 2011). The delineation and mapping of wetlands ecosystems is essential to promote ecosystem conservation and to develop ecosystem restoration with the assessment of drivers of environmental changes and the loss of hydrological connectivity.

Remote sensing has been an effective tool for characterizing, mapping, and monitoring the complexity and dynamics of large areas of wetlands. Several different sensors have been applied in wetland ecosystems, with great emphasis on spectral responses of wetland types in different parts of the electromagnetic spectrum (Tiner et al., 2015).

More recently, with the development of microwave sensors, the Synthetic Aperture Radar (SAR), the technology has been applied effectively in persistent cloud, smoke, and haze conditions (Lucas and Costa, 2018). The literature shows an increase use of SAR data for the study of wetlands: ALOS Phased Array L-band Synthetic Aperture Radar (PALSAR), European Remote Sensing (ERS-1), RadarSAT, ASAR, Japanese Earth Resources Satellite 1 (JERS-1), AIRSAR, and TerraSAR-X, Sentinel 1 (S1), are some of sensors applied in wetlands studies (Guo et al., 2017).

Previous studies have shown that low frequency bands ( $\mathrm{P}$ and $\mathrm{L}$ ) are better for detecting forest bogs, while higher frequency bands, such as $\mathrm{C}$ is most suitable for wetlands with dominant herbaceous vegetation (Kasischke et al., 1997; Baghdadi et al., 2001; Parmuchi et al., 2002; Henderson and Lewis, 2008). Zhang et al. (2019), addressed the capacity of the $\mathrm{S} 1$ sensor for wetland monitoring with promising results of $\mathrm{VH}$ versus VV polarization. Speckles are common features on SAR imagery and can produce noise that can troubled high precision classification, particularly when single polarization is applied (Bruzzone et.al., 2004). Multitemporal series have been considered as an alternative to improve classification quality (Quegan et al. 2000, Wegmüller et al. 2002, Bruzzone, et al. 2004, Tan et al. 2008, Wei et al. 2019, Zhang et al. 2019).

Along the last decade, successful studies with SAR technology have been developed in wetlands mapping throughout the world, such as Patuxent coastal plain in Maryland, USA (Lang and Kasischke, 2008), Pantanal in West Brazil (Evans et al, 2010), Bay of Mont-Saint-Michel, France (Betbeder et al., 2015), Newfoundland and Labrador, Canada (Mahdianpari et al., 2017), Ciénaga Grande de Santa Marta, and Poyang Lake in the central Yangtze, China (Zhang, Li and Wang 2019). Applications of SAR in disturbed wetlands with impaired hydrologic connectivity as a consequence of human impacts is a challenging opportunity for SAR technology (Jaramillo et al., 2018).

In the Lower Doce River Valley (LDRV), Southeastern Brazil, coastal wetland drainage for agriculture 
and pastureland development have lowered water table, exposing acid sulphate soils and decreasing soil $\mathrm{pH}$ as low as 3.5 (Lani et al., 2007). In the late years decreasing river discharge, in response to reduced rainfall and river regulation and fragmentation of cascade reservoirs for hydropower generation, produced short pulses of river discharge decreasing regularity of coastal plain flooding events.

This work aimed to develop an accurate wetlands mapping and related aquatic ecosystems of the Lower Doce River Valley (southeastern Brazil) with radar imagery of Sentinel 1, using multitemporal classification techniques and ground truth validation.

\section{MATERIALS AND METHODS}

\subsection{Study Area}

The Doce River Basin (DRB) spreads over 86,141 km2 in Southeast Brazil (Fig. 1). Climate is characterized with a tropical warm and rainy season, from October to March, and a mild dry season, from April to September. The mean annual rainfall at the LDRV is $1,123 \mathrm{~mm}$ (Linhares station 01839006). The lower river section is delimited from the border of Minas Gerais and Espírito Santo states towards the Atlantic Ocean. In the LDRV river channel drains PreCambrian, Tertiary and Quaternary geologic formations, with a network of alluvial valleys, river channels, lakes, wetlands and coastal plains.

The focal area of this study comprises two geomorphological unities: The Tertiary plateau formed of Barreiras Formation, and the Quaternary Coastal Plain. Barreiras plateaus are composed with sedimentary continental deposits with slightly sloping oceanward, dissected by a network of subparallel streams in narrow valleys with flat bottoms, presently silted up by Quaternary sediments. The coastal plain spreads along $130 \mathrm{~km}$ the north-south axis, with 30 $\mathrm{km}$ width in the river mouth (Fig. 1). Coastal geomorphology processes took place 5,100 years B.P. with a paleo deltaic formation and associated sea-level changes. The paleo lagoon was filled with alluvial, marsh and mangrove deposits (Martin et al., 1996a and b).

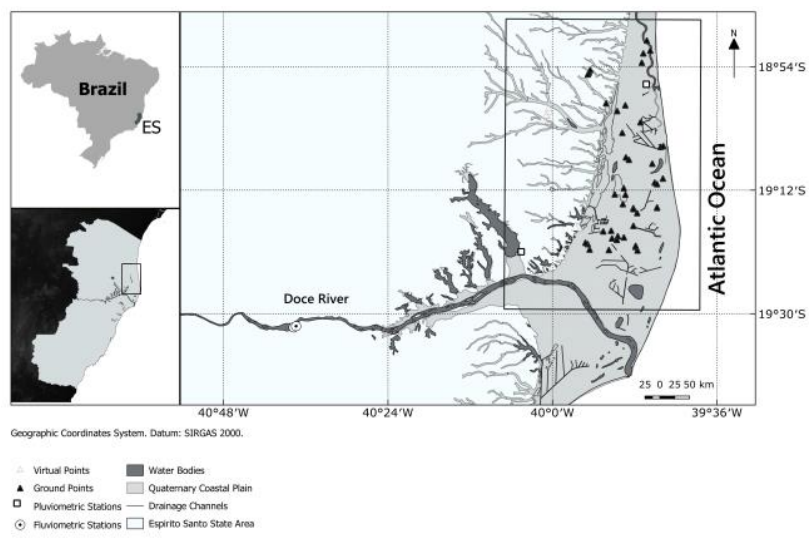

Figure 1: Lower Doce River Valley with the study area $(3,896.1$ $\mathrm{km}^{2}$ ) inside the rectangle.

The Doce River show a predictable monomodal hydrology pulse with a low amplitude (1.9m) (Junk et al., 2014). River discharge in the LDRV (Colatina station 56994510), $107 \mathrm{~km}$ upstream of the river mouth in the Atlantic Ocean, show mean high and low water discharges of 918 and $450 \mathrm{~m}^{3} \cdot \mathrm{s}^{-1}$, respectively. Despite the perennial condition from 1990 to 2013 river water discharge in the LDRV varied from 72 to 9,195 $\mathrm{m}^{3} \cdot \mathrm{s}^{-1}$ (Oliveira and Quaresma, 2017). Lower discharge has prevailed since 2014, with the years of 2014 and 2015 characterized with a very intensive drought (Nobre et al., 2016). Currently, the connectivity between the river channel and the coastal plain is restricted to major Doce River floods (> 2,500 $\mathrm{m}^{3} \cdot \mathrm{s}^{-1}$ ) such as December 2013 and January 2016. Mean monthly values of rainfall and river discharge are shown in Fig $2 \mathrm{a}$ and $\mathrm{b}$, respectively.
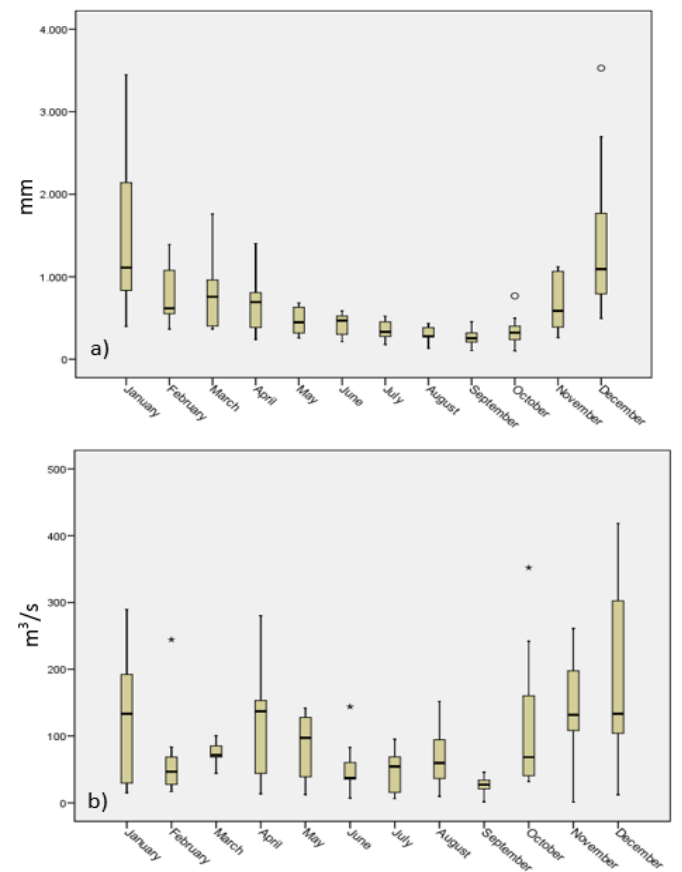

Figure 2: Mean annual values of rainfall (a) and river discharge (b) for the period of 2009 to 2018. Rainfall data were acquired from National Institute of Meteorology (INMET, 2019) and river discharge from National Water Agency (ANA) (SNIRH, 2019).

The impaired hydrological connectivity of LDRV coastal plain wetlands has been associated to the drainage works of the Brazilian federal government in the late 1960s, when a network of ditches was opened to drain wetlands for agriculture and pastureland conversion. The lowered water table has exposed organic hydromorphic soils, enriched with sulphates, to an oxidizing environment, resulting in low $\mathrm{pH}$ values (up to 3.5) (Lani et al. 2007).

On November 5th of 2015, in the upper section of the DRB, a collapsed iron ore tailing dam released $40 \times 10^{6} \mathrm{~m}^{3}$ of tailings, affecting nearly $600 \mathrm{~km}$ of river channel before reaching the ocean (Rudolf et al., 2018). Environmental impacts related to the technological disaster were considered within two exposures regimes a pulse disturbance (November 2015 to December 2016) and a press disturbance (2017 to 2029) (Magris et al., 2019). The flood of January 2016 caused the intrusion of tailings in the LDRV coastal plain.

\subsection{Synthetic Aperture Radar (SAR) imagery}

Ninety-one Interferometric Wide Swath (IW) Sentinel-1B Cband SAR imagery of LDRV were acquired $(10 \mathrm{~m}$ spatial resolution, VV/VH polarization) from Google Earth Engine platform. Imagery sorting criteria considered wet months for the period of October 2016 to October 2019. All images were 
obtained as Ground Range Detected (GRD) product, with the same acquisition geometry (path and incidence angles) through the Google Earth Engine (GEE). In GRD products a basic preprocessing has been already implemented (Zan and Guarnieri, 2006).

\subsection{Auxiliary geoinformation data}

A digital elevation model (DEM) of Shuttle Radar Topography Mission (SRTM) (30 m resolution) was used for Range-Doppler correction. Aiming to support field validation of wetland mapping, a 2012 land cover and land use (LULC) digital map at 1:25,000, and a 1:250,000 soil map was acquired from Espírito Santo Integrated Georeferenced Database (GEOBASES). A cross analysis between SAR imagery and LULC vectoral data was applied to detect land use changes along the dataset, specifically for permanent areas of open water and forest. Although, the LULC dataset is a certified reference for State of Espírito Santo, the vectorization process on $0.25 \mathrm{~m}$ spatial resolution of aerial photographs was manual, which might have induced to classification errors.

\subsection{Data processing and analysis}

Multitemporal SAR imagery were preprocessed with GEE scripts. Imagery preprocessing were carried out with metadata update of orbit, GRD border and thermal noise removal, radiometric calibration with backscattering coefficient $\left(\sigma^{\circ}\right)$. A geocodificacion for Range-Doppler range terrain correction was made using the digital elevation model (DEM) of Shuttle Radar Topography Mission (SRTM) (30 $\mathrm{m}$ resolution). The geocodification was set with UTM projection (24S zone) using WGS84 reference ellipsoid. Speckle removal was done with a Lee $7 \times 7$ refined filter (Lee, 1981). Geocodified imagery of backscattering coefficients were converted in $\mathrm{dB}$.

The study area $(3.986 \mathrm{~km} 2)$ is characterized by five LULC types: open waters, urban areas, exposed soils, agricultural areas, forests and wetlands. Time series were generated for some of these coverages (Figure 3). Each coverage shows a different temporal variability. The time series of the cross-polarization channel backscattering shows lower values in all cases, compared to the VV polarization channel. The open water areas present very low backscattering $(<-20 \mathrm{~dB})$ due to the specular reflection of the incident radiation that generates very small return backscattering. Urban and forestry areas in the SAR dataset shown low variability, indicating the perennial characteristics of these features.
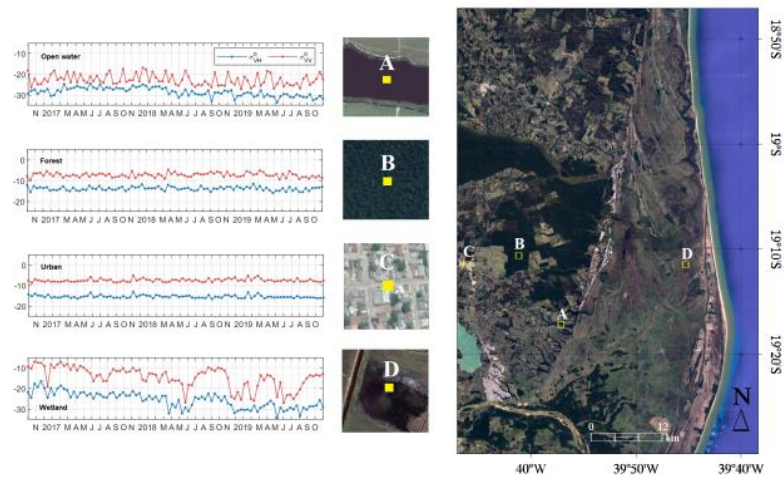

Figure 3. Time series of backscattering coefficient for different types of land cover and land use for the study area: deep water, forest, urban areas and wetland.
Variability of wetlands backscattering intensity are due to different factors. Non-flooded vegetation produces double bounce scattering resulting in high backscattering. Scattering of non-flooded vegetation is often described as volume scattering of diffuse nature and, therefore, generally not as bright as double bounce scattering (lower backscattering) (Tiner, 2015).

Since wetlands show high temporal variability a workflow for wetlands delineation and mapping with five main steps is illustrated in Figure 5. A median product of preprocessed imagery was generated for a typical of wet season (October-February). Median data also reduces the remaining speckle, facilitating imagery interpretability.

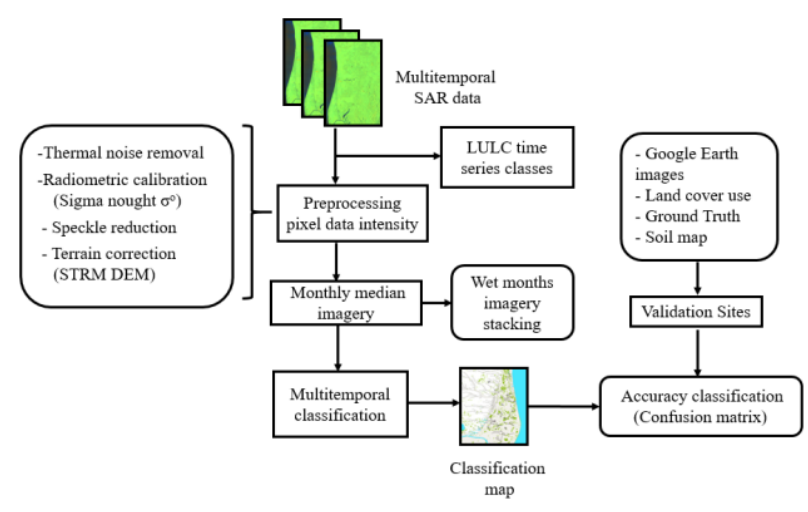

Figure 4. Workflow of multitemporal SAR imagery classification for wetland mapping.

GEE offers several unsupervised clustering algorithms including K-means, the algorithm that groups objects into $\mathrm{k}$ groups based on their characteristics. The latter is based on minimizing the sum of Euclidean distances between each object and the center of its cluster. This method yields few classes for analysis. Basically, it aims to compare the results of multiple interactions with different classes in order to select the best ones according to certain criteria. Three classes were selected: wetlands, open water and others.

\subsection{Field validation}

Fieldwork was carried out on August 16th 2019 with a river discharge of 530.7 m3.s-1 (dry season). Selected sites were chosen across the study area based on previous analysis from Google Earth imagery, aiming to include wetlands, open-waters and non-wetlands classes. Field positioning was based on GPS receiver and site features were registered with digital camera. A drone device was also employed for aerial imagery. The field survey described the LULC types, presenting six predominant classes: open waters, wetlands, urban areas, exposed soils, agricultural areas, and forests. The late four classes were merged in the class of non-wetlands

Validating sites for comparison of observed and modeled wetlands were based on fieldwork, soil map with preference for poorly drained hydromorphic soils, and wetland areas identified on Google Earth. Aiming to evaluate wetland mapping accuracy a Confusion Matrix between classified and reference data (i.e., wetlands, deep-water and non-wetlands) was applied. Users and producers' accuracies were verified using Kappa coefficient for global landscape features

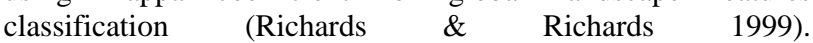




\section{RESULTS AND DISCUSSION}

The study yielded a total of 4,157 wetlands with an area of $262.27 \mathrm{~km} 2$, embracing $6.7 \%$ of the study area, with a pattern of very small patches $(0,06 \pm 0.31 \mathrm{~km} 2)$ (Figure 6). Shallow lakes associated with wetlands were classified as open water bodies with an area of $56.06 \mathrm{~km} 2$.

Wetlands and open water areas could be much larger if the classification process were more effective and regional and local rainfall were within the regular range during the study. The severe drought in southeastern Brazil during 2014 and 2015 (Nobre et al 2016) was considered the most extreme drought at the Rio Doce Basin for the last 30 years (Lima et al 2019). Since 2015, rainfall in the river basin, and particularly at LDRV, has been low, which can be regarded for the shrinkage and disappearance wetland areas. According to Lyra and Rigo (2019) the conversion forests by pasture reduces mean annual river discharge, with a decrease in mean flows. The authors suggest that deforestation increase flood events, while the annual minimum flows is reduced with deforestation.

Around $80 \%$ of wetlands is located in the coastal plain $(3,003$ ecosystems with an area of $210.52 \mathrm{~km} 2)$, while the other $20 \%(1,154$ wetlands with an area of $51.54 \mathrm{~km} 2)$ was found on the Barreiras plateau. The predominance of coastal plain wetlands was in response to a very gentle slope $(1.5 \%)$ and poorly drained hydromorphic soils, such as gley types rich in organic matter, quartz marine sands, hydromorphic podzols, and eutrophic cambisoils. LULC in the coastal plain is basically composed by pasture $(41.2 \%)$, sugar-cane $(3.4 \%)$, Eucalyptus sp forestry $(1.6 \%)$, and coconut culture $(0,6 \%)$. Natural features were represented by wetlands $(22.6 \%)$ in hydromorphic soils, forests $(17.5 \%)$ in cambisoils and restingas $(2.7 \%)$, a shrub vegetation formation on sandy soils.

In the Barreiras plateau, wetlands were associated with a gentle slope of 3.9\% and dystrophic yellow podzols with high clay content. LULC in the Barreiras Formation is much more diversified with wetlands $(6.6 \%)$, lakes $(6.5 \%)$, forest (17.2\%), pasture (6.7\%), Eucalyptus sp forestry (8.0\%), coffee (7.2\%) and sugar-cane (1.0\%) croplands.

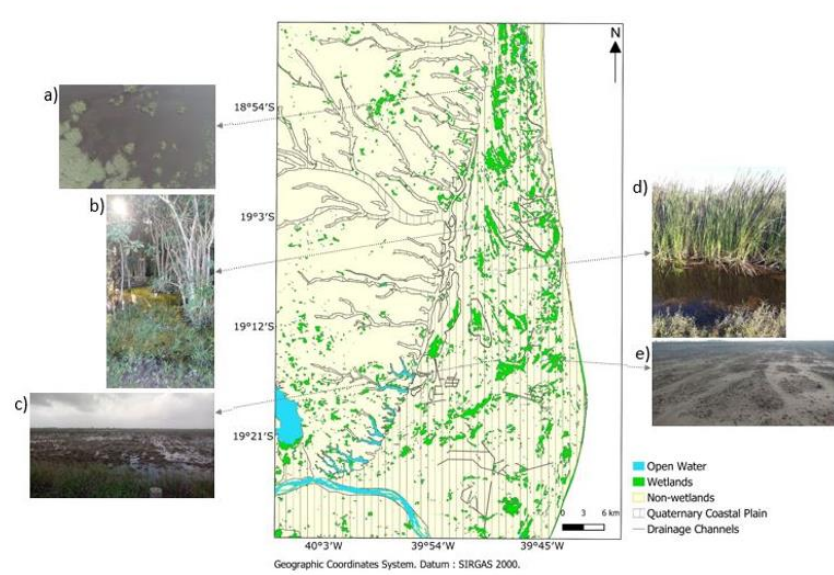

Figure 5. Wetlands mapped with SAR in the Barreiras formation and coastal plain, and examples of wetland typologies found in the study area. (a) freshwaters lagoons; (b) mixed forest; (c) artificial wetland; (d) monodominant herbaceous swamps of cattails, Typha dominguensis; and (e) peatland.
An attempt to define wetland typologies in the study area considering the classification scheme proposed for Brazilian wetlands (Junk et al 2014), considering pedological, hydrological and botanical criteria, has resulted in three main categories: inland wetlands, coastal wetlands, and artificial wetlands (Figure 7). Inland wetlands were found in the Barreiras formation and were most associated with freshwater lakes and monodominant herbaceous swamps of cattail, Typha dominguensis. Artificial wetlands were associated to irrigation reservoirs, road stream damming, and lowlands along roads. Coastal wetlands occurred in the coastal plain as without permanent connection to the sea and those without connection but with fluctuating level. Most of them are associated with waterlogged soils with shallow phreatic level and coastal lakes with different salinities. Drainage channels were important wetland features in the coastal plain. $T$. dominguensis swamps were also a common feature in coastal wetlands.

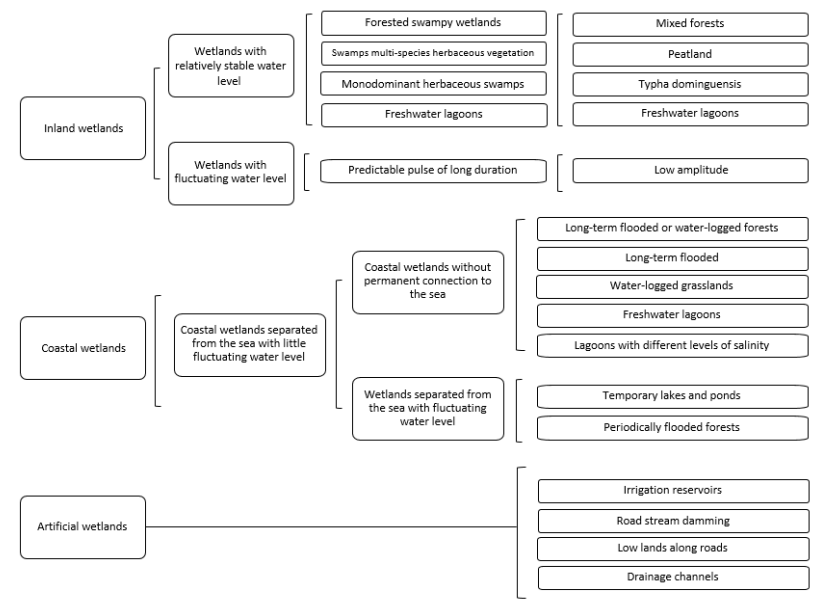

Figure 6. Wetlands types in Lower Doce River coastal plain based on Junk et al (2014).

\subsection{Field validation}

Field validation process was evaluated with a cross validation of LULC classes (i.e., wetlands, open water, non-wetlands) with 63 wetlands sites, 97 open waters, and 166 non-wetlands. A Confusion Matrix (Table 1) between reference data (i.e., LUL classes) and classified data (i.e., SAR median wet season condition) yielded an overall accuracy and Kappa coefficient of $81.9 \%$ and 0.71 , respectively. The lower accuracy of user wetland class $(<60 \%)$ can be regarded to the relatively small wetland area compared to other classes, besides can be confused with other land cover types, such as pasture and cropland. 
Table 1. Confusion matrix of K-means classification

Reference data

\begin{tabular}{lllll}
\cline { 2 - 4 } $\begin{array}{l}\text { Classified data } \\
\text { (Pixels) }\end{array}$ & Wetland & $\begin{array}{l}\text { Open } \\
\text { water }\end{array}$ & $\begin{array}{l}\text { Non- } \\
\text { wetland }\end{array}$ & $\begin{array}{l}\text { User's } \\
\text { accuracy }\end{array}$
\end{tabular}

$(\%)$

\begin{tabular}{llllll}
\hline Wetland & 47 & 7 & 36 & 52.22 \\
Open water & 1 & 90 & 0 & 98.90 \\
$\begin{array}{l}\text { Non-wetland } \\
\text { 15 }\end{array}$ & 0 & 130 & 89.65 \\
$\begin{array}{l}\text { Producer's } \\
\text { accuracy (\%) }\end{array}$ & 74.60 & 92.78 & 78.31 & \\
\hline
\end{tabular}

Despite the study missed a typical wet season with flooded coastal plain with high river discharges $\left(>2,500 \mathrm{~m}^{3} \cdot \mathrm{s}^{-1}\right)$ and shallow phreatic level, the tested approach is suitable as an alternative for optical sensors. The application of optical sensors can be severely restricted due to high cloud cover during wet seasons.

Even with the combination of VV/VH polarization of SAR imagery, which increases the capacity to discriminate open water, other targets can produce similar signatures of flooded vegetation. According to Tiner (2015) classification process is improved when polarimetric datasets are used. In the present study areas of flooded grasslands, herbaceous wetlands, such as T. dominguensis, and forested wetlands were misclassified as non-wetlands.

Finally, cloud computing of GEE was very helpful to handle massive dataset of multitemporal SAR imagery in a relative short time.

\section{CONCLUSIONS}

Recent advances in cloud computing create new opportunities to process large amounts of remote sensing data. Though the use of GEE to process Sentinel-1 images has been decisive for fast processing, but it has limitations in availability of unsupervised classification tools for wetland mapping.

The southeast region of Brazil presents remnants areas of wetlands, nevertheless, which are poorly mapped landscape features and under hydrological distress of water scarcity. The results of this study represent the first classification of the spatial distribution of wetlands in this region which is important for land reclamation management and conservation of these ecosystems.

It was achieved overall accuracy of $81,9 \%$ to the final map using the K-mean method and the accuracy of wetlands classification was $52,55 \%$, showing unsatisfactory results for this class. The open water class were detected with an accuracy close to $99 \%$, indicating the advantages of this methodology for the classification of water bodies.

\section{ACKNOWLEDGMENTS}

The authors would like to thanks CAPES (Federal Agency for Graduate Capacity Building) for scholarships and PROAPUFES for the financial support financial support for fieldwork. We also want to thanks Dr. Fábio Pavan Piccolli (LABESUL) for his support in the field.

\section{REFERENCES}

Baghdadi, N., Bernier, M., Gauthier, R., Neeson, I., 2001. Evaluation of C-band SAR data for wetlands mapping. International Journal of Remote Sensing, 22(1):71-88.

Barbier, E.B., Hacker, S.D., Kennedy, C., Koch, E.W., Stier, A.C., Silliman, B.R., 2011. The value of estuarine and coastal ecosystem services. Ecological Monographs, 81, 169-193.

Betbeder, J., Rapinel, S., Corgne, S., Pottier, E., Hubert-Moy, L. 2015., TerraSAR-X dual-pol time-series for mapping of wetland vegetation. ISPRS Journal of Photogrammetry and Remote Sensing, 107, 90-98.

Bruzzone L., Marconcini M., Wegmüller U., Wiesmann A., 2004. An advanced System for automatic classification of multitemporal SAR images. IEEE Transactions on Geoscience and Remote Sensing, 42(6):1321-1333.

Evans, T., Costa, M., Telmer, K., Silva, T., 2010. Using ALOS/PALSAR and RADARSAT-2 to map land cover and seasonal inundation in the Brazilian Pantanal. Journal of Selected Topics in Applied Earth Observations and Remote Sensing, 3-4:560-575.

Guo, M., Li, J., Sheng, C., Xu, J., Wu, L., 2017. A review of wetland remote sensing. Sensors, 17(4), 777.

Henderson, F.M., Lewis, A.J., 2008. Radar detection of wetland ecosystems: a review. International Journal of Remote Sensing, 29(20): 5809-5835.

IEMA - Instituto Estadual de Meio Ambiente e Recursos Hídricos Mapeamento ES (2012). Retrieved october 09, 2019, from https://geobases.es.gov.br/links-para-mapes1215.

INMET - Instituto Nacional de Meteorologia. Retrieved october 09, 2019, from http://www.inmet.gov.br/portal/index.php?r=estacoes/estacoesA utomaticas.

Jaramillo, F., Brown, I., Castellazzi, P., Espinosa, L., Guittard, A., Hong, S. H., Rivera-Monroy, V. R., Wdowinsk, S,. 2018. Assessment of hydrologic connectivity in an ungauged wetland with InSAR observations. Environmental Research Letters, 13(2): 024003.

Junk, W.J., Piedade, M.T.F., Lourival, R., Wittmann, F. Kandus, P., Lacerda, L.D., Bozelli, R.L., Esteves, F.A., Da Cunha, C.N., Maltchik, L., Schöngart, J., Schaeffer-Novelli, Y., Agostinho, A. A., 2014. Brazilian wetlands: their definition, delineation, and classification for research, sustainable management, and protection. Aquatic Conservation: Marine and Freshwater Ecosystems, 24:5-22. 
Kasischke, E.S., Melack, J.M., Dobson, M.C., 1997. The use of imaging radars for ecological applications - a review. Remote Sensing of Environment, 59:141-156.

Lang, M.W., and Kasischke, E.S., 2008. Using C-band synthetic aperture radar data to monitor forested wetland hydrology in Maryland's coastal plain, USA. IEEE Transactions on Geoscience and Remote Sensing, 46(2):535-546.

Lani, J.L., Rezende, S.B., Sartain, J.B., Lani, J.A. and Nascimento, P.C., 2007. "Desertos químicos" na região do delta do rio Doce (ES). In: Menezes, L. F.T., Pires, F.R. and Pereira, O.J. Ecossistemas costeiros do Espírito Santo: conservação e restauração. Vitória, EDUFES: 119-131.

Lee, Jong-Sen, 1981. Refined Filtering of Image Noise Using Local Statistics. Computer Graphics and Image Processing. 15, 380-389.

Lima, R., P.C., Silva, D. D., Moreira, M. C., Passos, J. B. M. C., Coelho, C. D. and Elesbon, A. A. A., 2019. Development of an annual drought classification system based on drought severity indexes. Anais da Academia Brasileira de Ciências, 91(1): e20180188.

Lucas, R., Costa, M., 2018. Remote sensing instruments: sensor types relevant to wetland. In: Finlayson, C.M., Everard, M., Irvine, K., McInnes, R.J., Middleton, B.A., Dam, A.A. v. and Davidson, N.C. The wetland book: I Structure and function, management, and methods, Springer.

Lyra, B. U., Rigo, D., 2019. Deforestation impact on discharge regime in the Doce River Basin. Ambiente e Agua-An Interdisciplinary Journal of Applied Science, v. 14, n. 4, p. 110.

Magris, R.A., Marta-Almeida, M.M., Monteiro, J.A.F., Banb, N.C. 2019. A modelling approach to assess the impact of land mining on marine biodiversity: Assessment in coastal catchments experiencing catastrophic events (SW Brazil). Science of The Total Environment, 659: 828-840.

Mahdianpari, M., Salehi, B., Mohammadimanesh, F. and Motagh, M., 2017. Random forest wetland classification using ALOS-2 L-band, RADARSAT-2 C-band, and TerraSAR-X imagery. ISPRS Journal of Photogrammetry and Remote Sensing, 130, 13-31.

Martin, L., Suguio, K., Flexor, J.M., Archanjo, J.D. 1996a. Coastal quaternary formations of the southern part of the State of Espírito Santo (Brazil). Anais da Academia Brasileira de Ciências, 68(3): 389-404.

Martin, L., Suguio, K., Flexor, J.M., Dominguez, J.M.L. and Bittencourt, A.C.S.P. 1996b. Quaternary sea-level history and variation in dynamics along the central Brazilian coast: consequences on coastal plain construction. Anais da Academia Brasileira de Ciências, 68(3): 303-452.

Mitsch, W.J. Gosselink, J.G., 1993. Wetlands. New York, Van Nostrand Reinhold Company.

Nobre, C.A., Marengo, J.A., Seluchi, M. E., Cuartas, L.A. and Alves, L.M., 2016. Some characteristics and impacts of the drought and water crisis in Southeastern Brazil during 2014 and 2015. Journal of Water Resource and Protection, 8(2): 252-262.
Oliveira, K.S.S., da Silva Quaresma, V., 2017. Temporal variability in the suspended sediment load and streamflow of the Doce River. Journal of South American Earth Sciences, 78, 101-115.

Parmuchi, M.G., Karszenbaum, H., Kandus, P., 2002. Mapping wetlands using multi-temporal RADARSAT-1 data and a decision-based classifier. Canadian Journal of Remote Sensing, 28(2):175-186.

Ramsar, 1971. Convention on wetlands. Ramsar, Iran. https://www.ramsar.org.

Richards, J. A., \& Richards, J. A. (1999). Remote sensing digital image analysis (Vol. 3, pp. 10-38). Berlin et al.: Springer.

Rudorff, N., Rudorff, C.M., Kampel, M., Ortiz, G., 2018. Remote sensing monitoring of the impact of a major mining wastewater disaster on the turbidity of the Doce River plume off the eastern Brazilian coast. ISPRS Journal of Photogrammetry and Remote Sensing, 145, 349-361.

Sentinel-1 Algorithms. Google Earth Engine API. Google Developers. Available online: https://developers. google.com/earth-engine/sentinel1 (accessed on 01 November 2019).

SNIRH, 2016. Sistema Nacional de Informação de Recursos Hídricos 2019. Retrieved 3 November, 2019, from http://www.snirh.gov.br/hidroweb/.

Tan C.-P., J.-Y. Koay, K.-S. Lim, H.-T. Ewe, and H.-T. Chuah, Classification of multi-temporal SAR images for rice crops using combined entropy decomposition and support vector machine technique, Progress In Electromagnetics Research, Vol. pier-83, 385, 2008

Tiner, R.W., Lang, M. W., \& Klemas, V.V., 2015. Remote sensing of wetlands: applications and advances. CRC press.

U.Wegmüller, A.Wiesmann, T. Strozzi, and C. L.Werner, "Forest mapping with multitemporal SAR," in Proc. ForestSAT'02 Conf., Edinburgh, U.K., Aug. 5-9, 2002.

Wei, S.; Zhang, H.; Wang, C.; Wang, Y.; Xu, L. MultiTemporal SAR Data Large-Scale Crop Mapping Based on UNet Model. Remote Sens. 2019, 11, 68.

Zhang, L., Li, B., Wang, B. 2019. Sentinel 1 Image Character Analysis for Mapping Wetland Vegetation. 1-4. 10.

\section{GEE FREE ACCESS LINK CODE}

https://code.earthengine.google.com/e143060ce9740837098139 147b910aa1 